\title{
How to Reduce Uncertainty in Supply Chains? The Role of the Interactive Control Lever
}

\author{
Nawfal BAHHA ${ }^{1} \&$ Imane El KARTIT ${ }^{1}$ \\ ${ }^{1}$ ENCG School of Busines, Marrakech, Morocco \\ Correspondence: Boulevard Allal Elfassi, ENCG, 40000 Marrakech, Morocco.
}

Received: April 19, 2021

Accepted: May 7, $2021 \quad$ Online Published: May 12, 2021

doi:10.5539/ibr.v14n6p68

URL: https://doi.org/10.5539/ibr.v14n6p68

\begin{abstract}
In the management control literature, several researchers have expressed the need to pay more attention to the integration of inter-organizational issues in the study of management control systems since the emergence of new forms of organizations. referred to as hybrids, networks, or even supply chains. In this article, we study supply chain management control through the prism of the interactive lever. The research adopts a qualitative analysis based on a theoretical framework based on the concept of the interactive lever of control developed by Simons (1995). The objective is to answer the following research question: how does the interactive dimension translate into supply chain management control and what is its contribution to the intra and inter-organizational management of the supply chain?
\end{abstract}

Keywords: supply chain management control, supply chain: uncertainty, interactive lever

\section{Introduction}

The increase in international trade in an ultra-competitive environment has led to the gradual substitution of the term logistics by the notion of supply chain (noted SC) which includes a more inter-organizational coordination of flows (Houé, 2020). In its broadest sense, a supply chain is defined as a logistics system made up of different companies (suppliers, manufacturers, distributors, logistics service providers, etc.) which seek to collectively best meet the demand of the end customer (Féniès, 2006). As part of the supply chain prospective circle organized on January 31, 2017 by Deloitte in partnership with Supply Chain Magazine, SC directors of large groups discussed the supply chain's contribution to company performance. These logistics directors confirmed that it is essential to go through the supply chain in order to develop. According to them, SC plays an important role in the strategic dimension of companies which are able to offer a competitive advantage through their supply chain. These companies say they cannot compete in the market without the support of other players in the supply chain. supply chain management has evolved towards an integrative and strategic, open and decompartmentalized approach, where the main challenge lies in the management of inter-organizational relations (Ageron et al. 2016).

Indeed, since the emergence of supply chain management, several researchers (Otley, 1994; Hopwood, 1996) have insisted on the need to take inter-organizational logic into account in management control systems. Now, a field of research has gradually developed around inter-organizational control and management control (Caglio and Ditillo, 2008; Van der Meer-Kooistra and Vosselman, 2009; Nogatchewsky, 2009). Several contexts have been studied in order to decipher the particularities and dimensions on which an inter-organizational management control system is based. In this regard, Mourey (2008) studied the control of inter-firm relations in the context of large-scale distribution. For his part, Nogatchewsky (2009) studied the configurations of management control in the context of customer-supplier relationships, while Goullet and Meyssonnier (2011) identified the different control levers implemented in service franchises. More recently, Lemaire (2013) has been interested in studying the process of building an inter-organizational management control tool within the framework of public / private partnerships. In addition, very little research deals with the management control of supply chains (Berry et al. 2009; Marques et al. 2011). This last observation is therefore at the origin of our research problem.

The research adopts a qualitative approach and relies on the interactive control lever developed by Simons (1995) to study supply chain management control. The objective is to answer the following research question: how is the interactive dimension reflected in supply chain management control and what is its contribution to the intra 
and inter-organizational management of the supply chain as a context marked by uncertainty?

Our research is structured around three main axes. In the first part, devoted to the literature review, we summarize the work on uncertainty and its sources. We explain what supply chain control is and in a final section, we look at the concept of the interactive control lever and its issue in the context of supply chains. The second part returns to the chosen research methodology. Finally, in a final part, we present and discuss the research results and end with a conclusion.

\section{Literature Review}

\subsection{The Supply Chain: A Context Marked by Uncertainty}

\subsubsection{Uncertainty in the Context of the Supply Chain}

Uncertainty can be likened to a lack of information about the factors associated with a given decision, the absence of knowledge about the possible outcomes of a decision, or the inability to assign reliable probabilities of the effect. environmental factors on a decision (Desreumaux 1998, p. 114). So why the uncertainty?

Indeed, with the emergence of supply chains, the perimeter of uncertainty has widened considerably. Today it goes beyond intra-organizational boundaries to reach an inter-organizational level (Spalanzani and Evrard Samuel, 2007). Uncertainty is therefore located at all levels of a supply chain (internal, inter-organizational and external). Likewise, many researchers have been interested in studying uncertainty from a broad perspective by analyzing its dimensions in the context of supply chains (Prater et al. 2005, Gao et al. 2005, Wu and Rao. 2007, Rodrigues et al. 2008). A current of research has therefore gradually developed around "Supply chain uncertainty".

In the context of the supply chain, Koh and Tan (2006) consider that supply chain uncertainty can be defined as the inability to correctly assess the impacts of possible control actions on the behavior of the supply chain, and to implement effective control actions. For other authors (Van der Vorst and Beulens, 2002), uncertainty within supply chains refers to decision-making situations, in which the decision-maker does not know exactly what to decide on a final basis, either by lack of information in the supply chain or its environment, lack of capacity in information processing, inability to accurately predict the impact of control actions on the behavior of the supply chain, or the lack of effective control actions.

The following section details the different sources of uncertainty.

\subsubsection{Sources of Uncertainty within Supply Chains}

Despite the importance and wealth of research on uncertainty, its sources are sometimes difficult to identify. Abernethy and Mundy (2014) confirm this observation by specifying that "we still do not have a good understanding of the sources of uncertainty, how individuals respond to uncertainty and how organizations can design systems and processes to support managers operating in uncertain environments". In the same vein, Lepori and Bollecker (2015) underline in their research that the context of supply chains is subject to several strategic uncertainties which therefore require collecting and generating information on their sources. Among the research that has looked at this axis in the specific context of supply chains, we can cite the work of Kibli et al. (2010). These authors distinguish three types of uncertainties within a supply chain:

- "Usual" uncertainty: linked to relatively traditional data such as demand, production costs or transport time. The impact linked to this difficulty in estimating these parameters, which can be the subject of probability distributions, is considered to be relatively low.

- Uncertainty linked to "chance": relating to events having a low chance of occurring but whose consequences on the system considered are very important. This is for example the case of natural disasters such as hurricanes or earthquakes which can lead to the destruction of entities within the system considered.

- "Deep" uncertainty: it corresponds to situations for which no probability of occurrence can be assigned to the realization of different scenarios of values for one or more parameters (Lempert et al. 2006). These researchers also identified three sources of strategic uncertainty: endogenous (or internal) sources, sources related to supply chain partners (or inter-organizational) and exogenous (or environmental) sources.

Thus, in his research carried out within the Hewlett-Packard company in 2008-2009, Ruel (2013) identified several types of uncertainties linked to the supply chain environment: uncertainty linked to demand, uncertainty linked to the supply chain. 'supply, uncertainty linked to technological developments, uncertainty linked to competition, uncertainty linked to changes in regulations. Within the same framework of analysis, the work of Van der Vorst and Beulens (2002) makes it possible to distinguish eight sources of uncertainty: 
- Uncertainties inherent in the supply chain: characteristics of products, demand, processes and supply.

- Uncertainties related to the configuration of the supply chain: chain infrastructure, parallel interactions, installations.

- Uncertainties related to the control structure of the supply chain: time to obtain information and the decision-making process, time to supply, production and distribution, administrative and decision-making procedures, complexity of decisions.

- Uncertainties related to supply chain information systems: data chronologies, data accuracy and applicability, information availability.

- Uncertainties related to the organizational structure of the logistics chain: authority and responsibility, human behavior.

Ultimately, we can see that supply chains evolve in a context characterized by strong strategic uncertainty. The latter can have several sources: endogenous (or internal), sources linked to supply chain partners (or inter-organizational) and exogenous (or environmental) sources. Consequently, supply chains "tend to be" critical paths "where the slightest incident can, by propagation, spill over to the end customer" (Fabbe-Costes, 2005). The management of the logistics process throughout the supply chain therefore depends on the ability of each of the actors involved to meet their commitments and, where applicable, to face risks; a failure of one of the partners or a hazard outside the process can compromise the success of the whole at any time. In such a context marked by strong strategic uncertainty, control (mastery) and interactive management and inter-organizational processes is a key factor for the performance of the supply chain. Hence the need for management control adapted to the supply chain.

\subsection{Towards Supply Chain Management Control}

Analysis of the various work carried out on supply chain management control shows that there is no clear and precise definition of what a supply chain management control system is. In fact, most of the research has focused on instrumental aspects, management control tools and the main steering axes around the management of costs, flows (physical, information and financial) and logistics and supply performance. chain. However, the research conducted by Horch (2009) is more comprehensive since it focuses on several aspects of the supply chain; at the same time instrumental, organizational and functional. Indeed, this research consists of analyzing the management control systems of global supply chains, focusing more particularly on large German groups.

Horch (2009) defines a supply chain management control system as a set of institutional, functional and instrumental elements that support supply chain management in the management and control of inter-organizational physical, information and financial flows with the different parties involved in the supply chain.

- By institutional elements, the author refers to the organizational structure of the supply chain and its management control. It specifies in this sense that "Supply Chain structures, especially on the management control level, require the adoption of new organizational solutions, especially with regard to integration and collaboration (...). The organizational structure shall consider the special role and status of interdependent departments and firms which are responsible for the supply chain management control "

- By functional elements, the author refers to the different modes of intra and inter-organizational coordination set up to facilitate the exchange and sharing of information between the different units involved in supply chain management control.

- By instrumental elements, the author cites various tools or techniques developed in the management control literature. In this sense, he specifies that "firms must extend their focus to systems that measure overall supply chain performance. This requires comprehensive costing, budgeting.

Supply chain management control should be considered as a system that includes different subsystems encompassing functional, institutional and instrumental aspects to support supply chain management in the planning, evaluation and management of processes and flows between the different actors at internal and external levels of the supply chain. It is therefore necessary to work in collaboration and in transversality in the control of the management of the supply chain.

To this end, the "multi-level" scope of supply chain management control depends on the degree of integration of the inter-organizational dimension. In this regard, three main levels of supply chain management control have been highlighted, as shown in the table below. 
Table 1. Supply chain management control organisation

\begin{tabular}{|c|c|c|c|}
\hline & Low level & Average level & High level \\
\hline $\begin{array}{l}\text { Inter-organizational } \\
\text { teams }\end{array}$ & $\begin{array}{l}\text { No team at inter-organizational } \\
\text { level }\end{array}$ & $\begin{array}{l}\text { Inter-organisational } \\
\text { teams in some cases }\end{array}$ & $\begin{array}{l}\text { Collaborative control unit for } \\
\text { supply chain management with } \\
\text { permanent inter-organisational } \\
\text { teams }\end{array}$ \\
\hline $\begin{array}{lr}\begin{array}{l}\text { Supply } \\
\text { management }\end{array} & \text { chain } \\
\text {-leadership } & \\
\end{array}$ & $\begin{array}{l}\text { Leadership through a centralized } \\
\text { unit with a top-down approach }\end{array}$ & $\begin{array}{l}\text { Leadership through a } \\
\text { centralized unit with a } \\
\text { top-down approach }\end{array}$ & $\begin{array}{l}\text { Division of the leadership role } \\
\text { internally as well as between } \\
\text { some supply chain partners }\end{array}$ \\
\hline $\begin{array}{l}\text { Cooperation in supply } \\
\text { chain management } \\
\text { control }\end{array}$ & $\begin{array}{l}\text { No direct exchange of } \\
\text { information between supply } \\
\text { chain partners and less effort in } \\
\text { collaboration activities }\end{array}$ & $\begin{array}{l}\text { Collaboration on } \\
\text { information exchange at } \\
\text { the operational level }\end{array}$ & $\begin{array}{l}\text { High level of collaboration and } \\
\text { exchange of all supply chain } \\
\text { information }\end{array}$ \\
\hline
\end{tabular}

Source : Adapted from Horch (2009)

In summary, we can retain three characteristic dimensions of a supply chain management control system: the multi-level dimension which refers to the levels of intra and inter-organizational management; the multi-actor dimension which refers to the multiplicity and variety of actors belonging to the same supply chain; and the instrumental dimension which refers to management control tools which must be adapted to the specificities of the supply chain. It is based on two management axes: intra and inter-organizational management of logistics flows (physical, information and financial): and management of the operational and financial performance of the supply chain.The implementation of such a supply chain management control system requires strong inter-functional and inter-organizational collaboration based on exchange and interactivity.

\subsection{The Issue of the Interactive Dimension in Supply Chain Management Control Systems}

The conceptual framework developed by Simon is widely used in the management control literature. Several researchers have been inspired by this theoretical framework and have shown its relevance to explain the relationships between control and strategy mainly in intra-organizational contexts (Berland et al. 2016). In fact, Simons (1995) distinguishes four control levers making it possible to highlight the interactions between strategic steering and management control: delimitation systems, belief systems, diagnostic control systems and interactive control systems. . Each of these levers plays a role with respect to a parameter of strategic management, both in the sense of the implementation of the strategy internally and the control of its relevance externally.

- The delimitation system: regulates risk-taking and plays a binding, limiting role in the search for new opportunities. This system sets limits on certain areas of management, but does not prevent all creativity and innovation.

- The belief system: formal and informal controls fundamental values and guides the search for new opportunities in an uncertain environment.

- The diagnostic control system: focuses on performance deviations from clearly pre-identified objectives; it is based on a relatively stabilized performance measurement system. This control is akin to cybernetic control of a closed system; the organization would not be subject to turbulence in its environment.

- The interactive control system: addresses the strategic areas of uncertainty identified by the leaders. It is not the nature of the formal control system that inscribes it in diagnostic control or in interactive control, but the way in which it is mobilized for decision-making by managers. This control requires intensive use by both top managers and operational staff, regular debates during management points and meetings and a particular focus on strategic uncertainties.

Indeed, the interactive lever constitutes a relevant framework for studying supply chain management control, in view of the strategic uncertainty that characterizes supply chains but also because of its multi-level and multi-actor dimensions, which require transversal management. processes and consequently generates interactions between different actors at both intra-organizational and inter-organizational level.

In the same sense, the supply chain considered as an interactive matrix platform (Fiore, 2014), links the horizontal and vertical performance management. It constantly requires new forms of coordination between company directors and operational managers. As a result, the management of supply chain flows cannot be ensured in a linear and unidirectional manner. The alignment of interests between different actors seeking to have their visions accepted supposes exchange and negotiation, it also sometimes supposes modification or 
adaptation of management control systems. It therefore seems important to provide formal and informal spaces for discussion relating to management control systems and contributing to the flexibility of the articulation between internal and inter-organizational management control systems.

\section{Method}

Due to the exploratory nature of our research problem and the scarcity of work that is interested in it, the qualitative approach has naturally emerged as the most relevant approach for studying supply chain management control. The collection of qualitative data was mainly carried out through semi-structured individual interviews. Qualitative data make it possible to grasp and contextualize the way in which individuals live, represent themselves and explain their experiences (Miles and Huberman, 2003). They also allow new situations to emerge which had not been envisaged a priori by the researcher and thus enrich interpretations of reality.

The research methodology (see figure 1) is marked by three main stages. In a first step, we carried out an exploratory study on professional socio-digital networks by studying the profile descriptions (one to two pages) of 50 supply chain management controllers in France in different sectors of activity. (secondary data). In a second step, we conducted expert interviews with teacher-researchers in management control and members of the DFCG (secondary and primary data). In the third step, we carried out semi-structured interviews with key informants directly involved in supply chain management control: supply chain management controllers and supply chain managers.

\section{Results and Discussion}

Taking into account the two multi-level and multi-actor dimensions of the supply chain, we have observed that the interactive lever of supply chain management control manifests itself through a dual intra-organizational (vertical and horizontal) and inter-organizational interactivity. (external). In this sense, the results of our research show that supply chain management control promotes communication, discussion and exchange at different levels: between senior managers (general management, financial management); middle managers (logistics director, supply chain director, sales director, supply chain management control director, etc.); middle managers (supply chain managers, logistics management controllers, purchasing management controllers, etc.); and operational (supply manager, transporters, etc.). The two forms of interactivity are complementary. However, they differ in relation to the actors involved in them, in relation to the objectives but also in relation to the exchange mechanisms (formal and informal put in place).

We have chosen to present the results punctuated from time to time by illustrative verbatim. Although practice tends to append them, we have found it necessary and more informative to display them in the body of the text in order to make the connection between theory and practice through the speech of key informants.

\subsection{Interactive Lever of Control: Towards a Dual Intra-Organizational and Inter-Organizational Interactivity}

\subsubsection{Forms of Intra-Organizational Interactivity of the CGSC}

\section{- Internal actors involved in the CGSC}

We first present the main "internal" players involved in supply chain management control and with whom the supply chain management controller interacts. We made this choice to analyze the interactivity from the supply chain management controller which is located at the interface between the two levels of strategic and operational management. As the verbatim below illustrate, some respondents pointed out that this dual strategic and operational positioning of supply chain management control allowed them to have an overview of the supply chain. It has also contributed to the evolution of their field of piloting.

"I started out as a supply chain management controller and today I am responsible for the supply chain. So I have an overview on the different areas"RCGSC-E14

This vision is in line with the point of view of Bouquin and Fiol (2006) who indicate that "management control is torn between its component which serves general management (a financial approach) and that which regulates" the field "and its processes.

The advantage of supply chain management control is also that it leads to this interactivity. (...) a supply chain management controller will release a lot of data, a lot of indicators that constitute our work elements ie. that we have to meet a lot with all the members of the supply chain. »RCGSC-E14

Analysis of the data shows that the latter interacts with actors who are located at different hierarchical levels. First, there are senior executives, including general management, financial management and supply chain management, who deal with financial and strategic supply chain issues. In this regard, a supply chain management that we interviewed attests that the supply chain management controller is involved in strategic 
decision-making and is part of the management committee.

The supply chain management controller is part of the management committee, all strategic subjects are discussed and are defined with management controllers even in the quotations, he is involved in the budgets that are defined at the end of the year. He is strongly involved, he brings us help and we need the management controller because without management control, we cannot measure the costs and consequently we cannot control them, we cannot measure our margins, we cannot define our selling prices correctly. SCM-E18

Then, middle managers and operational staff belonging to different functions or professions and who are more involved in operational and transversal issues (inter-functions and inter-professions) of the supply chain.

This first category of intra-organizational interactivity therefore takes two forms: a first vertical interactivity and a second horizontal interactivity.

\section{- Vertical interactivity with senior executives}

As we have just presented, the first level of interactivity is more oriented towards the strategic and financial management of the supply chain. Indeed, issues related to supply chain management control are, first of all, monitored by top management (general management, head office, regional directors, etc.) and the main managers involved in the management of the supply chain at strategic level (logistics directors, supply chain directors, logistics platform directors, plant directors, etc.). These different actors, during monthly, quarterly or annual meetings, discuss and discuss together on the financial and non-financial performance of their supply chain and take strategic decisions to improve its functioning and its intra and inter-organizational management. They also discuss major logistics projects and their profitability, in particular to integrate a new supplier, adopt a new delivery method, etc.

As part of these meetings or what the interviewees call "Performance Business Reviews", the supply chain management controllers are required to take stock of the results obtained (reporting) and discuss avenues for improvement. Thanks to the discussions that take place, new ideas appear and promote the emergence of new strategic directions for the supply chain.

- Regular horizontal interactivity (transversal and inter-business) with directors and managers at intermediate decision-making levels

In supply chain management control, the interactive control lever is not limited to only vertical exchanges between senior executives and managers or intermediary executives. Vertical interactivity is supplemented by frequent exchanges between intermediate managers (supply chain managers, supply chain management controllers, service directors, etc.) and with operational staff or operators who are closer to the field. In this sense, supply chain management controllers and supply chain managers play a central role in articulating the two strategic and operational levels. The objectives of horizontal interactivity consist mainly in seeking causal links between operational performance and financial performance by approaching operational units in order to support them in the management of their activities. To this end, meetings are organized at different rates: daily, weekly and monthly, as the following comments illustrate:

"In supply chain management control, we find the elements of interface management. What is specific to the supply chain is more to adapt its discourse to operational staff. It's more complicated to work between buyers, logisticians, production engineers, it's certainly not quite the same rhetoric, so you have to know how to adapt. $»$ RCGSC-E15

"Absolutely, the interaction is different if you will because we go around the table so the interaction with the profession is a little different. For example, we organize weekly meetings, we discuss operational indicators, while with the finance department we will be more involved in the production of financial indicators. The operational part will be within the supply chain department. »CGSC-E1

"In the supply chain, my team is divided into different themes, first there is a purchasing management controller, a transport and customs management controller, a logistics management controller and a stock management controller. »RCGSC-E10

"My role is just to lead these meetings, each operator suggests things, we brainstorm, and they have defined indicators that they measure every day and we lead meetings every morning (...). Today it is a group dynamic at the platform level and at the warehouse level. After me I consolidate and I have more macro indicators that allow better management of all activity as a whole and with a global vision of customers, suppliers and the entire chain. »SCM-E18 
The transversal nature of the interactive lever of supply chain management control systems is highlighted by the remarks summarized in the table below. The latter presents the main players involved with supply chain management controllers in this type of horizontal and transversal interactivity as well as its objectives and exchange mechanisms. We also specify that the results revealed the existence of a strong interactivity between supply chain managers and supply chain management controllers. Intra-organizational interactivity manifests itself in meetings organized on a daily, weekly or monthly basis by middle managers and operational staff involved in supply chain management. Given the diversity of these exchanges and their frequency, intra-organizational interactivity can be described as strong. The closer you get to the field, the more frequent the monitoring becomes.

"It's a lot of meetings, it's a minimum of one meeting per week with all the players in our company, it's all department managers meet once a week to discuss all these topics. It looks much easier when there are larger or more complicated projects we can go from 3 to 4 meetings per week. »RCGSC-14

"There are monthly meetings with the sales directors who will confirm the needs and afterwards the needs are revalidated in duo in the machine according to what will tell us both the sales directors and the marketing directors, so there is a monthly meeting with sales directors, marketing directors, general management, planners and logistics management. »DL-E3

"We piloted the supply chain on a weekly basis, ie every week we held update meetings to follow up on the proposed corrective actions. »CGL-E19

"I like to apply the dynamics of project management to my teams in order to seek continuous improvement in results, processes and organizations. »CGSC

As illustrated by the words of a logistics director, to facilitate intra-organizational interactivity and promote exchanges and the emergence of new ideas, several exchange mechanisms are favored, in particular "group expert processes", continuous improvement, the "Teams Boards":

"There are tools that will favor this transversality and this transparency, transparency in meetings with the use of" Team Boards ", everyone will express their progress, their difficulties in a common way and this is done at all levels: at at the level of the finance department, at the level of the supply chain department, etc. We will work on the continuous improvement workshops, and we will put all the people, and when there is a recurring problem that occurs, the different actors of the company involved we will put them together and we go after points of continuous improvement, therefore, these are the two tools that we use to decompartmentalize ourselves. We will also promote that everyone can contribute ideas; for example someone in the warehouse who will give an idea for marketing, etc. So we will promote exchanges by rewarding ideas. »DL-E3

"We have what we call 'expert group processes'. Every quarter, we bring together people from the factories and the supply chain who will talk about their issues and the improvements that can be made either in terms of visibility or in terms of efficiency. »DL-E3

As we have just seen, the interactive lever of supply chain management control does not only take place vertically (between senior managers and their subordinates). Our results show, in accordance with the literature (Gautier, 2000; Berland and Presiaux, 2008; Renaud, 2009), that vertical interactivity is complemented by transversal interactivity between executives and middle managers (supply chain managers, supply chain managers, supply chain controllers). chain, sales managers, purchasing managers, etc.) and operational staff (inventory managers, carriers, handlers, forklift operators, etc.).

It is in this transversality, as Loing et al. (2003), that the main sources of performance improvement lie, especially as at this level, the frequency of monitoring and exchanges intensifies. This dual vertical and transversal interactivity, as mentioned by the interviewees, promotes collective learning in the management of logistics flows in the supply chain and the emergence of new ideas and solutions to improve the operational and ultimately financial performance of the supply chain. chain.

In addition to vertical and transversal interactivity, empirical results show that there is also a form of interactivity that we qualify as inter-organizational. In fact, interactivity is first reinforced internally between executives, managers and other departments, then complemented by interactivity at a broader and external level with suppliers, distributors and customers. In the following paragraph, we present how inter-organizational or external interactivity manifests and translates into supply chain management control. 


\section{Conclusion}

- Theoretical contributions

The first theoretical contribution lies not only in the description of management control within logistics chains, but also in a more detailed understanding of the concept itself of CGSC. The second theoretical contribution lies in the analysis of management controls in a reticular context, marked primarily by the implementation of an interactive logic involving several actors who must learn to coordinate as well as possible. Indeed, the literature has long focused on an intra-organizational approach to control. While intern-organizational relationships have been the subject of several studies, very few studies have looked at management control within the supply chain.

In fact, in the speeches of the various respondents, the key concepts on the interactive lever of control such as exchange, dialogue, discussion, interaction, were omnipresent. This confirms the importance of the interactive lever in supply chain management control. Due to its multi-level and multi-actor nature, the management of the supply chain requires numerous exchanges or confrontations of ideas between several actors, both internally and externally. These players, managers, management controllers, supply chain managers, logistics directors, operational managers are more numerous and diverse as the logic of management and the scope of supply chain management control is disseminated at different intra and inter levels. -organization of the supply chain. In this regard, we have identified two types of complementary interactivity to ensure the management of intra and inter-organizational flows of the supply chain and to promote the emergence of new solutions or opportunities.

The first theoretical contribution lies not only in the description of management control within logistics chains, but also in a more detailed understanding of the concept itself of CGSC. The second theoretical contribution lies in the analysis of management controls in a reticular context, marked primarily by the implementation of an interactive logic involving several actors who must learn to coordinate as well as possible. Indeed, the literature has long focused on an intra-organizational approach to control. While intern-organizational relationships have been the subject of several studies, very few studies have looked at management control within the supply chain.

A first intra-organizational interactivity oriented towards the strategic steering (interactions between top management and middle management) and operational (interactions between middle management and operational staff) of flows at the level of the internal supply chain. Intra-organizational interactivity is therefore both vertical and horizontal. The main exchange mechanisms cited by respondents are face-to-face meetings. These can be organized at several times (weekly, monthly, quarterly, or annually) and at different levels of the organization. Other devices were mentioned by respondents such as continuous improvement workshops, "process group experts", "controlling school", etc.

A second inter-organizational interactivity is important to complete the first intra-organizational interactivity and therefore to better understand the inter-organizational constraints of the supply chain. Inter-organizational interactivity is more oriented towards inter-organizational or external management of the supply chain.

To facilitate inter-organizational interactivity with external players in the supply chain, several exchange mechanisms are favored, in particular face-to-face meetings around a table, videoconferences, telephone or Skype calls, or physical presence of one or more representatives with an external actor in the supply chain.

\section{- Managerial contributions}

The main contribution of the article lies in the highlighting of the interactive lever in the understanding and analysis of the dimensions of the CGSC marked by the preponderance of uncertainty, which in our eyes constitutes a useful opening for the understanding of the supply chain. contemporary chains in various industries.

\section{- Limits and perspectives}

The main limitation of this work is that it has focused in the empirical part on two players in the supply chain, yet the latter is more reticular and more extensive. In future research, there is a need for in-depth case studies by analyzing the perspectives of several stakeholders. Thus, it will certainly help to have a more complete picture of the supply chain.

In addition, it would be interesting to carry out comparative studies in the contexts of different supply chains. We believe that the agro-food sector would be different from that of the automobile or the aeronautics in the sense that the degree of uncertainty would be distinct. Indeed, a sector marked by few players would be less uncertain than one marked by the scope of participants (automotive).

\section{References}

Ageron, B., Carbone, V., \& Lavastre, O. (2016). Les grands auteurs en logistique et Supply Chain Management. Éditions EMS. 
Bahha, N. (2016). La satisfaction de la relation fournisseur de marque de distributeur (MDD)-distributeur: explication par le prisme de la proximité (Doctoral dissertation, Aix-Marseille).

Bahou, O., N, Bahha, I, \& El Kartit. (2021). La gestion des conteneurs endommagés dans un terminal à conteneur: quels apports de la digitalisation? 5 ème conférence internationale PROLOG, Nantes, France.

Berland, N., \& Persiaux, F. (2008). Le contrôle des projets d'innovation de haute technologie. Comptabilité-Contrôle-Audit, 14(2), 75-106. https://doi.org/10.3917/cca.142.0075

Berland, N., Deville, A., Piot, C., \& Capkun, V. (2016). 20 ans de publications en CCA... et des projets pour encore 20 ans !. Comptabilité-Contrôle-Audit, 22(1), 7-26. https://doi.org/10.3917/cca.221.0007

Berry, A. J., Coad, A. F., Harris, E. P., Otley, D. T., \& Stringer, C. (2009). Emerging themes in management control: A review of recent literature. The British Accounting Review, 41(1), 2-20. https://doi.org/10.1016/j.bar.2008.09.001

Bouquin, H., \& Fiol, M. (2007). Le contrôle de gestion: repères perdus, espaces à retrouver. In « comptabilité et environnement » (pp. CD-Rom).

Caglio, A., \& Ditillo, A. (2008). A review and discussion of management control in inter-firm relationships: Achievements and future directions. Accounting, Organizations and Society, 33(7), 865-898. https://doi.org/10.1016/j.aos.2008.08.001

Deschenaux, F. (2007). Guide d'introduction. Les cahiers pédagogiques de l'Association pour la recherche qualitative.

Fabbe-Costes, N. (2007). La gestion des chaînes logistiques multi-acteurs: les dimensions organisationnelles d'une gestion lean et agile. La gestion de la chaîne logistique multi-acteur: perspective stratégique, Grenoble : PUG.

Féniès, P. (2006). Une méthodologie de modélisation par processus multiples et incrémentiels: application pour l'évaluation des performances de la Supply Chain. Doctorat en Sciences de gestion, Clermont-Ferrand: Université Blaise Pascal-Clermont-Ferrand II.

Fiore, C. (2014). Les nécessaires mutations du Contrôle de Gestion au travers du Management coût-qualité-délai : Vers le Pilotage des Performances? Les Dossiers de Recherche en Economie et Gestion, DOREG. https://doi.org/10.12816/0030885

Gao, T., Sirgy, M. J., \& Bird, M. M. (2005). Reducing buyer decision-making uncertainty in organizational purchasing: can supplier trust, commitment, and dependence help? Journal of Business Research, 58(4), 397-405. https://doi.org/10.1016/S0148-2963(03)00137-1

Goullet, C., \& Meyssonnier, F. (2011). Le contrôle des réseaux de franchise. Comptabilité-Contrôle-Audit, 17(1), 99-121. https://doi.org/10.3917/cca.171.0099

Hopwood, A. G. (1996). Looking across rather than up and down: on the need to explore the lateral processing of information. Accounting, Organizations and Society, 21(6), 589-590. https://doi.org/10.3917/cca.171.0099

Horch, N. (2009). Management control of global supply chains. BoD-Books on Demand.

Houé, (2020). Impact de la diversité des relations acheteur-fournisseurs sur la gestion responsable des achats : une explication par les proximités.

Idrissi, M. O., \& Bahha, N. (2019). Research in logistics and supply chain management conducted in Morocco: A systematic review of literature from 2010 to 2018. Prolog conference, Metz, France.

Kibli, W., Martel, A., \& Guitouni, A. (2010) .The design of robust value-creating supply chain networks: a critical review. European Journal of Operational Research, 203, 283-293. https://doi.org/10.1016/j.ejor.2009.06.011

Koh, S. C. L., \& Tan, K. H. (2006). Translating knowledge of supply chain uncertainty into business strategy and actions. Journal of Manufacturing Technology Management. https://doi.org/10.1108/17410380610662898

Lemaire, C. (2013). Le processus de construction d'un outil de contrôle de gestion inter-organisationnel : le cas de l'expérimentation d'un outil de pilotage de la performance dans le secteur médico-social. Doctorat en sciences de gestion, Strasbourg: Université de Strasbourg.

Lempert, R. J., Groves, D. G., Popper, S. W., \& Bankes, S. C. (2006). A general, analytic method for generating robust strategies and narrative scenarios. Management science, 52(4), 514-528.

https://doi.org/10.1287/mnsc.1050.0472 
Lepori, E., \& Bollecker, M. (2015). Les leviers de contrôle de SIMONS: vers une compréhension des freins à l'équilibrage diagnostic/interactif. In Comptabilité, Contrôle et Audit des invisibles, de l'informel et de l'imprévisible (pp. cd-rom).

Löning, H., Malleret, V., Méric, J., \& Pesqueux, Y. (2013). Contrôle de gestion-4e éd : Des outils de gestion aux pratiques organisationnelles. Dunod. https://doi.org/10.3917/dunod.lonin.2013.01

Marques, L., Ribeiro, J. A. \& Scapens, R. W. (2011). The Use of Management Control Mechanisms by Public Organizations with a Network Coordination Role: A Case Study in the Port Industry. Management Accounting Research, 22, 269-291. https://doi.org/10.1016/j.mar.2011.09.001

Miles, M. B., \& Huberman, A. M. (2003). Analyse des données qualitatives. De Boeck Supérieur.

Mourey, D. (2008). Le contrôle circulaire Une approche socio-organisationnelle du contrôle des relations stratégiques inter-firmes dans le secteur de la grande distribution, Doctorat en sciences de gestion, Paris: Université Panthéon-Sorbonne-Paris I.

Mourey, D. (2009). Les impensés des approches décontextualisées du contrôle des relations inter-firmes. La place de la dimension européenne. Comptabilité Contrôle Audit, May 2009, Strasbourg, France.

Nogatchewsky, G. (2009). Contrôle inter-organisationnel. Encyclopédie de comptabilité, contrôle de gestion et audit, 625-633.

Otley, D. (1994). Management control in contemporary organizations: towards a wider framework. Management accounting research, 5(3), 289-299. https://doi.org/10.1006/mare.1994.1018

Prater, E., Frazier, G. V., \& Reyes, P. M. (2005). Future impacts of RFID on e-supply chains in grocery retailing. Supply Chain Management: An International Journal. https://doi.org/10.1108/13598540510589205

Renaud, A. (2009). Le système de management environnemental comme moyen de contrôle de la déclinaison et de l'émergence des stratégies environnementales. Doctorat en sciences de gestion, Poitiers : Université de Poitiers.

Ruel, S. (2013). Maîtrise des incertitudes de l'environnement de la chaîne logistique: une analyse au regard du décalage entre théorie et pratique? Doctorat en sciences de gestion, Grenoble: Université de Grenoble.

Sanchez-Rodrigues, V., Potter, A., \& Naim, M. M. (2010). Evaluating the causes of uncertainty in logistics operations. The International Journal of Logistics Management. https://doi.org/10.1108/09574091011042179

Simons, R. (1995). Levers of control: how managers use innovative control systems to drive strategic renewal. Harvard Business School Press, Boston, Massachusetts.

Spalanzani, A., \& Samuel, K. E. (2007). Absorbing uncertainty within supply chains. International Journal of Productivity and Quality Management, 2(4), 441-458. https://doi.org/10.1504/IJPQM.2007.013337

Van Den Bogaard, M. A., \& Speklé, R. F. (2003). Reinventing the hierarchy: strategy and control in the Shell Chemicals carve-out. Management Accounting Research, 14(2), 79-93. https://doi.org/10.1016/S1044-5005(03)00020-9

Van Der Vorst, J. G., \& Beulens, A. J. (2002). Identifying sources of uncertainty to generate supply chain redesign strategies. International Journal of Physical Distribution \& Logistics Management. https://doi.org/10.1108/09600030210437951

Wu, W., \& Rao, S. S. (2007). Uncertainty analysis and allocation of joint tolerances in robot manipulators based on interval analysis. Reliability Engineering \& System Safety, 92(1), 54-64. https://doi.org/10.1016/j.ress.2005.11.009

\section{Copyrights}

Copyright for this article is retained by the author(s), with first publication rights granted to the journal.

This is an open-access article distributed under the terms and conditions of the Creative Commons Attribution license (http://creativecommons.org/licenses/by/4.0/). 